\title{
Escin induces caspase-dependent apoptosis and autophagy through the ROS/p38 MAPK signalling pathway in human osteosarcoma cells in vitro and in vivo
}

\author{
Jian Zhu ${ }^{1,2,4}$, Wei Yu ${ }^{1,2,4}$, Bing Liu ${ }^{1,2,4}$, Yitian Wang ${ }^{1,2,4}$, Jianlin shao ${ }^{3}$, Junjie Wang ${ }^{1,2}$, Kaishun Xia ${ }^{1,2}$, Chengzhen Liang ${ }^{1,2}$, \\ Weijing Fang ${ }^{1,2}$, Chenhe Zhou ${ }^{1,2}$ and Huimin Tao*,1,2
}

Osteosarcoma is one of the most malignant neoplasms in adolescents, and it generally develops multidrug resistance. Escin, a natural mixture of triterpene saponins isolated from Aesculus hippocastanum (horse chestnut), has demonstrated potent antitumour potential in vitro and in vivo. In the present study, we found that escin inhibited osteosarcoma proliferation in a dose- and time-dependent manner. Additionally, escin-induced apoptosis was evidenced by the increased expression of caspase-related proteins and the formation of apoptotic bodies. Escin also induced autophagy, with elevated LC3, ATG5, ATG12 and Beclin expression as well as autophagosome formation. Inhibition of escin-induced autophagy promoted apoptosis. Moreover, p38 mitogen-activated protein kinases (MAPKs) and reactive oxygen species (ROS) were activated by escin. A p38 MAPK inhibitor partially attenuated the autophagy and apoptosis triggered by escin, but a ROS scavenger showed a greater inhibitory effect. Finally, the therapeutic efficacy of escin against osteosarcoma was demonstrated in an orthotopic model. Overall, escin counteracted osteosarcoma by inducing autophagy and apoptosis via the activation of the ROS/p38 MAPK signalling pathway; these findings provide evidence for escin as a novel and potent therapeutic for the treatment of osteosarcoma.

Cell Death and Disease (2017) 8, e3113; doi:10.1038/cddis.2017.488; published online 12 October 2017

Osteosarcoma is one of the most malignant primary bone tumours, primarily affecting adolescents and young adults. ${ }^{1,2}$ Whereas conventional chemotherapy is an important treatment option for osteosarcoma, it has many disadvantages. ${ }^{3}$ For example, chemotherapeutics tend to be highly toxic to normal tissues, leading to anaemia, neutropenia, thrombocytopenia, heart damage and a series of adverse reactions, thereby decreasing the patient survival rate. ${ }^{4,5}$ Therefore, new agents with fewer side effects and better therapeutic benefits are needed.

Escin, the main active compound of horse chestnuts, ${ }^{6}$ has been widely used to treat swelling, exudation, and inflammation. ${ }^{7}$ Recently, accumulated experimental evidence has shown that escin is a potential cancer chemotherapeutic and has elucidated some of the underlying mechanisms. ${ }^{8-10}$ However, the principal mechanism underlying its anti-tumour effect is not fully understood. Furthermore, the effects of escin effect on human osteosarcoma and its underlying mechanisms have not been reported.

Apoptosis is the classic mechanism by which chemotherapy agents induce cell death; ${ }^{11}$ however, numerous studies have shown that these drugs also induce autophagy. ${ }^{12}$ Autophagy is usually considered to be a critical process by which cells recycle ineffectual cellular components to maintain homeostasis. This process plays a critical role in programmed cell death type II, which can be exploited to suppress tumour growth. ${ }^{13}$ Paradoxically, autophagy also serves as a cell survival pathway. ${ }^{14,15}$ Previous studies ${ }^{16,17}$ have demonstrated the dual roles of autophagy in neoplastic development; it can function as a suppressor of early-stage carcinoma and a promoter of later stage disease. ${ }^{18}$ Hence, the relationship between apoptosis and autophagy has not been fully elucidated, especially in the context of escin-induced osteosarcoma cell death.

Increasing evidence supports that mitogen-activated protein kinases (MAPKs) mediate apoptosis and autophagy in response to chemotherapy. ${ }^{19,20}$ MAPKs are key players in the regulation of cell proliferation and cancer development. Activation of p38 MAPK could augment the processes of apoptosis and autophagy. ${ }^{21}$ Meanwhile, MAPK signal transduction cascades could be regulated by reactive oxygen species (ROS). ${ }^{22-24}$

Intracellular redox status has been reported to be associated with carcinogenesis and antineoplastic processes. ${ }^{25,26} \mathrm{ROS}$ are small and highly reactive molecules that play key roles in regulating physiological processes and maintaining redox balance. ${ }^{27}$ Although an appropriate amount of intracellular ROS conditions can improve cell proliferation. Recent studies $^{28,29}$ have reported that excessive amounts of ROS cause oxidative damage to cells, especially malignant cells, by

\footnotetext{
${ }^{1}$ Department of Orthopedics, 2nd Affiliated Hospital, School of Medicine, Zhejiang University, \#88 Jie Fang Road, Hangzhou, Zhejiang 310009, PR China; ${ }^{2}$ Orthopedics Research Institute of Zhejiang University, \#88, Jiefang Road, Hangzhou 310009, PR China and ${ }^{3}$ La Jolla Institute for Allergy and Immunology, La Jolla, CA, USA *Corresponding author: H Tao, Department of Orthopedics, 2nd Affiliated Hospital, School of Medicine, Zhejiang University, \#88 Jie Fang Road, Hangzhou, Zhejiang 310009, PR China. Tel/Fax: +86 5718778 3578; E-mail: 2187040@ zju.edu.cn

${ }^{4}$ These authors contributed equally to this work.

Received 06.4.17; revised 05.8.17; accepted 09.8.17; Edited by GM Fimia
} 


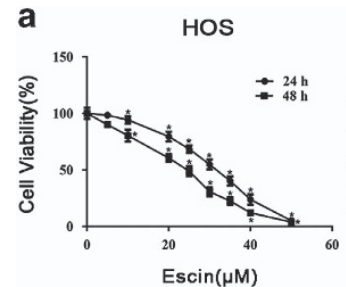

b
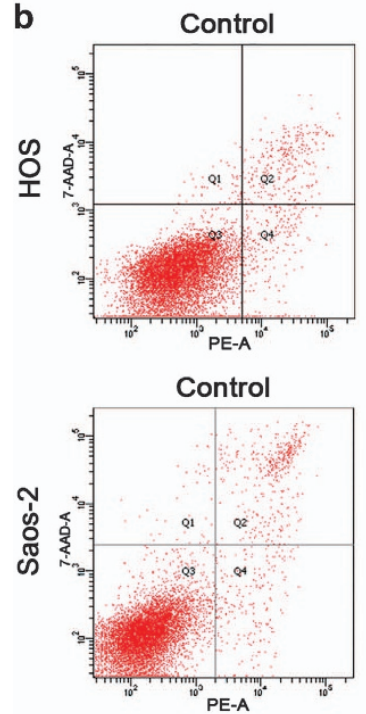

d

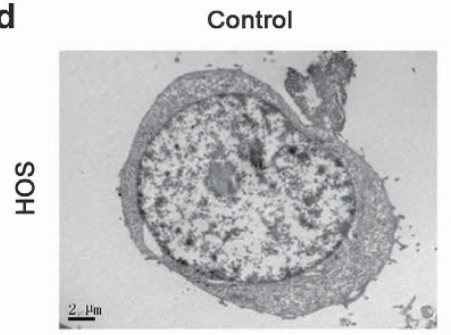

$\underline{\underline{2 \mu}}$

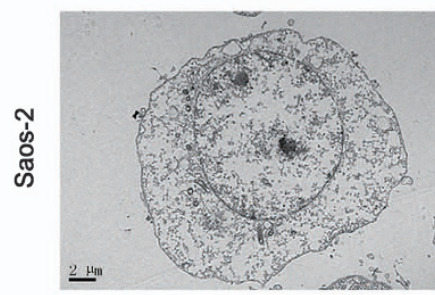

Saos-2
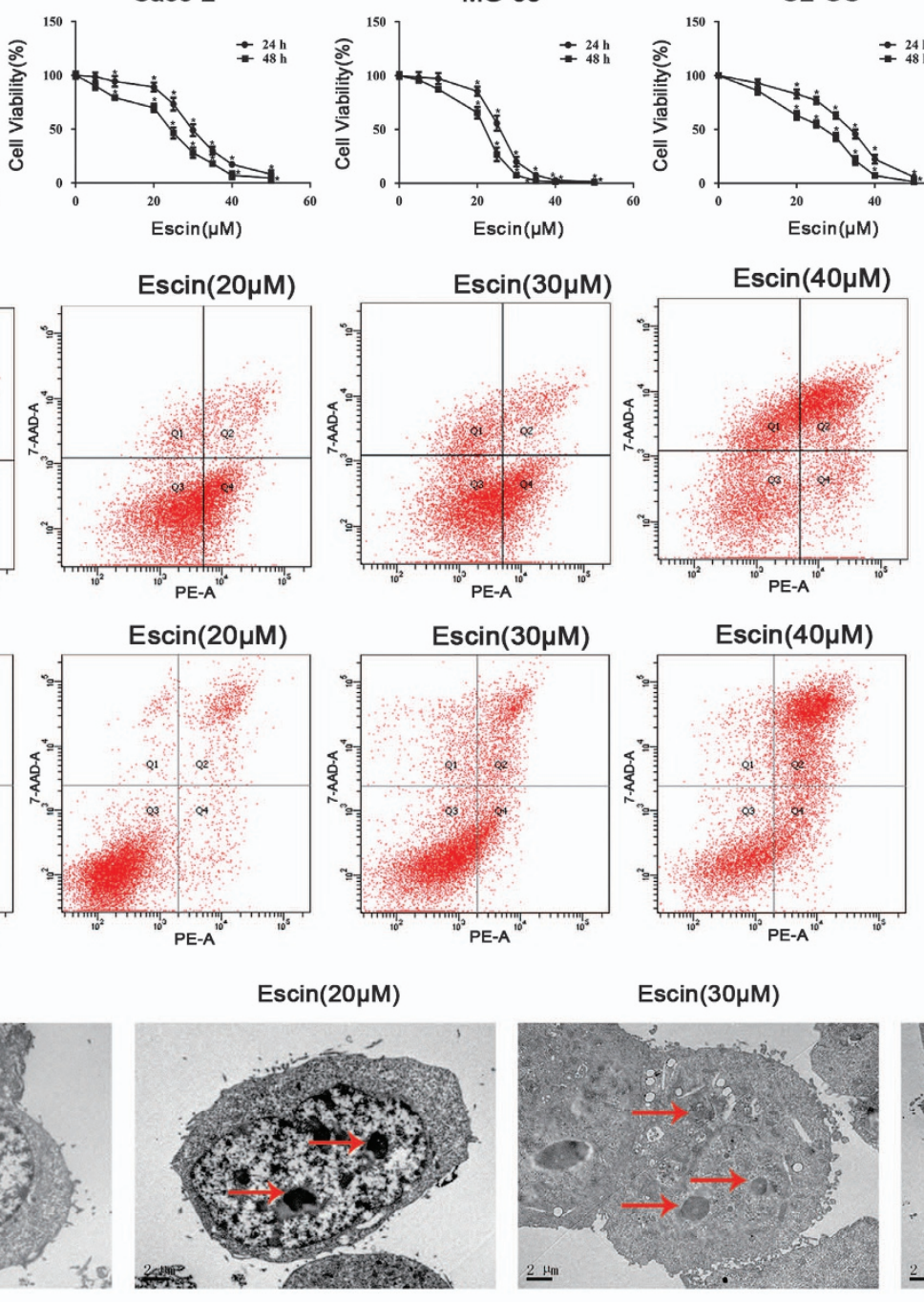

$\operatorname{Escin}(20 \mu \mathrm{M})$

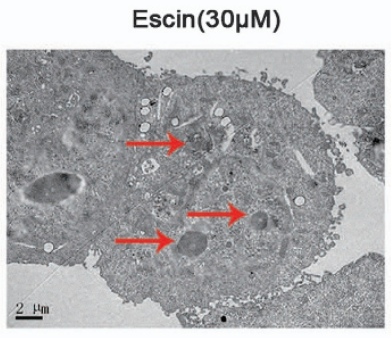

$\operatorname{Escin}(30 \mu \mathrm{M})$
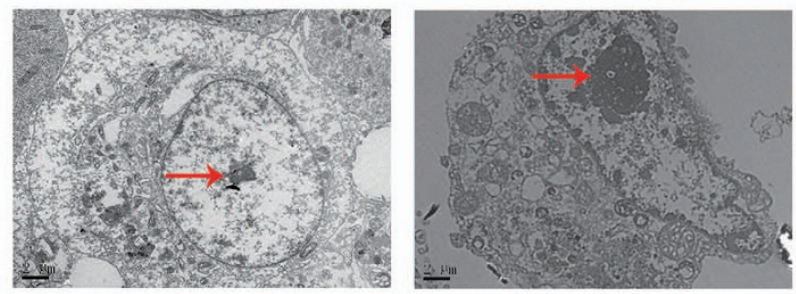
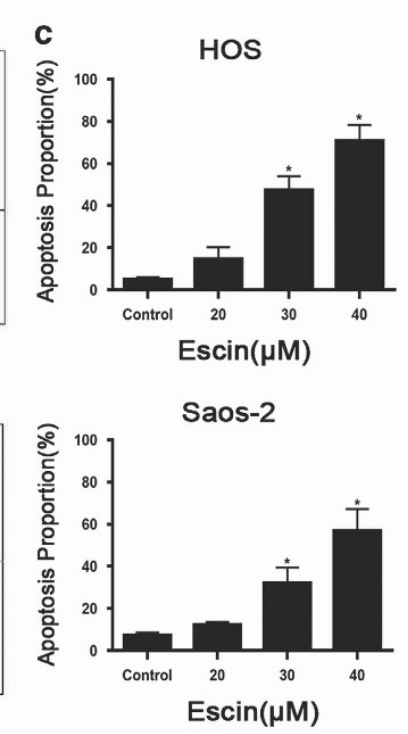

HUVEC

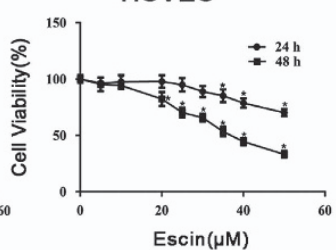

$\operatorname{Escin}(40 \mu M)$

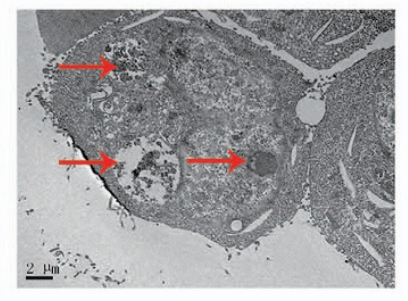

$\operatorname{Escin}(40 \mu \mathrm{M})$

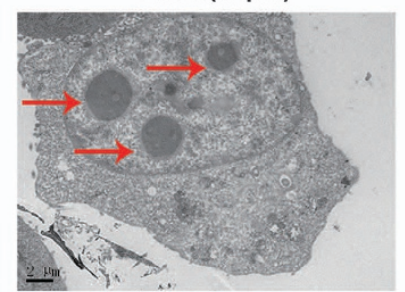

Figure 1 Escin inhibits human osteosarcoma cell proliferation through apoptosis. (a) Four osteosarcoma cell lines and HUVEC cells were treated with different concentrations of escin for 24 or $48 \mathrm{~h}$. MTS assays were performed. The control group was treated with $0.1 \%$ DMSO. The data are presented as the mean of six replicates, and each experiment was performed three times. (b,c) The HOS and Saos-2 osteosarcoma cell lines were incubated with escin or control for $24 \mathrm{~h}$, stained with an Annexin V-PE/7-AAD kit and analysed by flow cytometry. The proportion of apoptotic cells is presented as the mean \pm S.D. of three replicate experiments. (d) Apoptotic morphology was observed by transmission electron microscopy. The red arrows indicate apoptotic bodies and nuclear condensation. Scale bar, $2 \mu \mathrm{m}$. ${ }^{*} P<0.05$ compared with control

inducing autophagy and apoptosis. Accordingly, targeting relevant signalling pathways, especially the ROS and p38 MAPK pathways, may be a good choice for osteosarcoma treatment.

In the current study, we demonstrated that escin has antitumour potential against osteosarcoma. We further investigated the underlying mechanisms, and the results suggest that escin may induce apoptosis and autophagy in osteosarcoma through the ROS/p38MAPK pathway.

\section{Results}

Escin has an anti-proliferation effect on osteosarcoma. To investigate the effect of escin on tumour growth, four osteosarcoma cell lines MNNG/HOS, Saos-2, MG-63 and U2-OS were exposed to different concentrations of escin for 24 or $48 \mathrm{~h}$. Then, cell viability was evaluated using the MTS assays (Figure 1a). The IC50 of escin at $24 \mathrm{~h}$ was $30.44 \mu \mathrm{M}$ 
for HOS cells, $29.93 \mu \mathrm{M}$ for Saos-2 cells, 25.51 $\mu \mathrm{M}$ for MG-63 cells, and $32.40 \mu \mathrm{M}$ for U2-OS cells. Moreover, in the previous studies, ${ }^{30}$ escin shows cytotoxic effects on control cell especially after treatment with escin at $48 \mathrm{~h}$. Furthermore, our study showed that escin has less cytotoxic effects on control cell at $24 \mathrm{~h}$ than $48 \mathrm{~h}$, so $24 \mathrm{~h}$ treatment is beneficial for cancer studies. The IC50 value of escin for HUVEC cells was $95.81 \mu \mathrm{M}$ for $24 \mathrm{~h}$ and $37.92 \mu \mathrm{M}$ for $48 \mathrm{~h}$. These results indicated that escin could inhibit the proliferation of osteosarcoma cells in a time- and dose-dependent manner. MNNG/HOS and Saos-2 cells harbour mutant p53 and are more chemoresistant to current chemotherapeutics; ${ }^{31,32}$ these cells were used in subsequent assays. We chose concentrations of 20,30 and $40 \mu \mathrm{M}$ escin and a timepoint of $24 \mathrm{~h}$ for the following experiments based on data from previous studies. ${ }^{33-35}$

Escin induces apoptosis in osteosarcoma cells. To determine whether apoptosis is responsible for escininduced cell death, we detected apoptotic cells, apoptosisrelated proteins and morphological changes. Annexin-PE/PI staining results indicated that escin induced the apoptosis of osteosarcoma cell lines (Figure 1b). The apoptosis percentage of HOS cells in $40 \mu \mathrm{M}$ group is $70.8 \%$, which is significantly higher than $5.13 \%$ in control group. The Saos-2 cells apoptosis percentage in $40 \mu \mathrm{M}$ group is $56.93 \%$, which is 11 times greater than the apoptosis percentage in control group. Consistent with the MTS results, escin induced the apoptosis of osteosarcoma cells in a dose-dependent manner (Figure 1c). As shown in Figure 1d, nuclear condensation and apoptotic bodies were clearly observed. Figure $2 \mathrm{a}$ shows the appearance of apoptotic chromatin condensation and DNA fragmentation. Overall, these results demonstrate that escin induces apoptosis in osteosarcoma cells.

Escin induces caspase-dependent apoptosis through mitochondrial-mediated pathways. To explore the molecular mechanism of escin-induced apoptosis, we performed western blots to assess apoptosis-related proteins. As shown in Figure $2 \mathrm{~b}$ and Supplementary figure 1, the protein levels of cleaved caspase-3, -7, -8, -9 and poly(ADPribose) polymerase (PARP) was 1.85, 1.28, 1.2, 1.53 and 2.03 times higher than control group of HOS and 2.7, 1.37, 1.41, 1.66 and 3.21 times higher than control group of Saos-2 after treatment with $40 \mu \mathrm{M}$ escin, respectively. Bcl-2 family members are known to be involved in the mitochondrial-mediated apoptosis pathway, which activates the caspase cascade. ${ }^{36}$ Thus, we investigated $\mathrm{Bax}, \mathrm{Bcl}-\mathrm{XL}$ and $\mathrm{Bcl}-2$ key members of the $\mathrm{Bcl}-2$ family. Escin of $40 \mu \mathrm{M}$ group upregulated Bax protein levels (1.46 times higher than control group in HOS and 2.61 times higher than control group in Saos-2) and downregulated the expression level of $\mathrm{Bcl}-\mathrm{XL}$ (decreasing 63\% than control group in $\mathrm{HOS}$ and $51 \%$ than control group in Saos-2) and Bcl-2 (decreasing 39\% than control group in HOS and 53\% than control group in Saos-2) (Figure 2b and Supplementary figure1). These results indicate that escin induces caspasedependent apoptosis through mitochondrial-mediated pathways.
Escin induces autophagy in osteosarcoma cells. As autophagy is involved in an alternative cell death mechanism, we explored its role in escin-induced tumour inhibition. First, transmission electron microscopy (TEM) was used to directly confirm autophagosome formation (Figure 3a). LC3 is an important regulator of autophagy that promotes autophagosome formation and ATG5 and ATG12 form a complex that is essential for autophagy. ${ }^{37}$ The ATG5-ATG12 complex promotes the conjugation of LC3BI to phosphatidylethanolamine to form LC3BII, which is then recruited to autophagosomal membranes. ${ }^{38}$ Figure $3 \mathrm{~b}$ shows that escin upregulated the levels of LC3BII, ATG-5, ATG-12 and Beclin-1 and downregulated $\mathrm{LC} 3 \mathrm{IB}$ levels, indicating that escin regulates autophagy. Next, we investigated whether escin-induced autophagy contributes to cell death. Cell viability was assessed in the presence of 3-MA (an autophagy inhibitor) or z-VAD-fmk (an apoptosis inhibitor). 3-MA moderately reduced escin-induced cell death, while z-VAD-fmk strongly reduced cell death (Figure $3 \mathrm{c}$ ). These data suggest that escin-induced autophagy promotes cell death and that escin causes both apoptotic and autophagic cell death.

Escin inhibits osteosarcoma through the p38 MAPK pathway. The activated MAPK signalling pathway can induce cell death in cancer. ${ }^{39}$ Thus, we explored whether this pathway is activated by escin in osteosarcoma. The expression levels of p38, JNK and ERK-2 were determined by western blot analysis. Escin upregulated p38 expression in a dose- and time-dependent manner (Figure 4a) but had a minimal impact on JNK and ERK-2 (data not shown). Furthermore, when cells were precultured with the p38 MAPK inhibitor, the proportion of apoptotic cells and the expression of apoptosis- and autophagy-related proteins were decreased (Figures $5 \mathrm{~b}-\mathrm{e}$ ). These results indicated that the p38 MAPK pathway is essential for escin-induced apoptosis and autophagy.

Escin-induced ROS initiates apoptosis and autophagy in osteosarcoma cells through the ROS/p38 MAPK pathway. ROS usually plays an important role in regulating apoptosis and autophagy. ${ }^{40,41}$ Thus, Escin-treated osteosarcoma cells were stained with DCFH-DA to assess ROS generation. As shown in Figures $4 b$ and $c$, escin induced ROS generation in a dose-dependent manner. The ROS scavenger $\mathrm{N}$-acetyl L-cysteine (NAC) was used to confirm the role of ROS in escin-induced cell death. NAC decreased ROS levels (Figure 4d). Less autophagic vacuoles and chromatin condensation were observed in cells pretreated with NAC than the p38/MAPK inhibitor (Figure 5a). Moreover, NAC reversed escin-induced death and apoptosis proportion to a greater extent than the p38/MAPK inhibitor (Figures $5 b-d)$. In addition, NAC inhibited the escin-induced activation of apoptosis and autophagy-related proteins and strongly blocked p38 phosphorylation (Figure 5e). These results revealed that ROS may be the important factor upstream of p38 MAPK that initiates escin-induced apoptosis and autophagy.

Escin inhibits osteosarcoma in vivo. To simulate the circumstance of osteosarcoma in vivo, we established an 


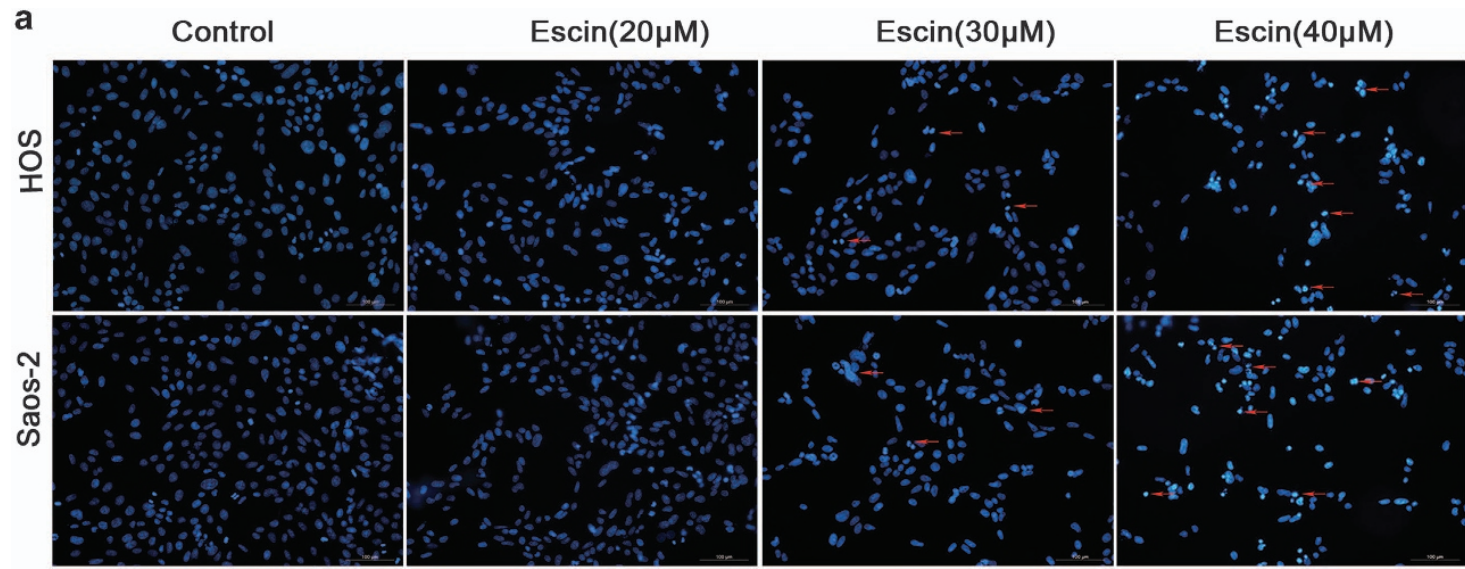

b
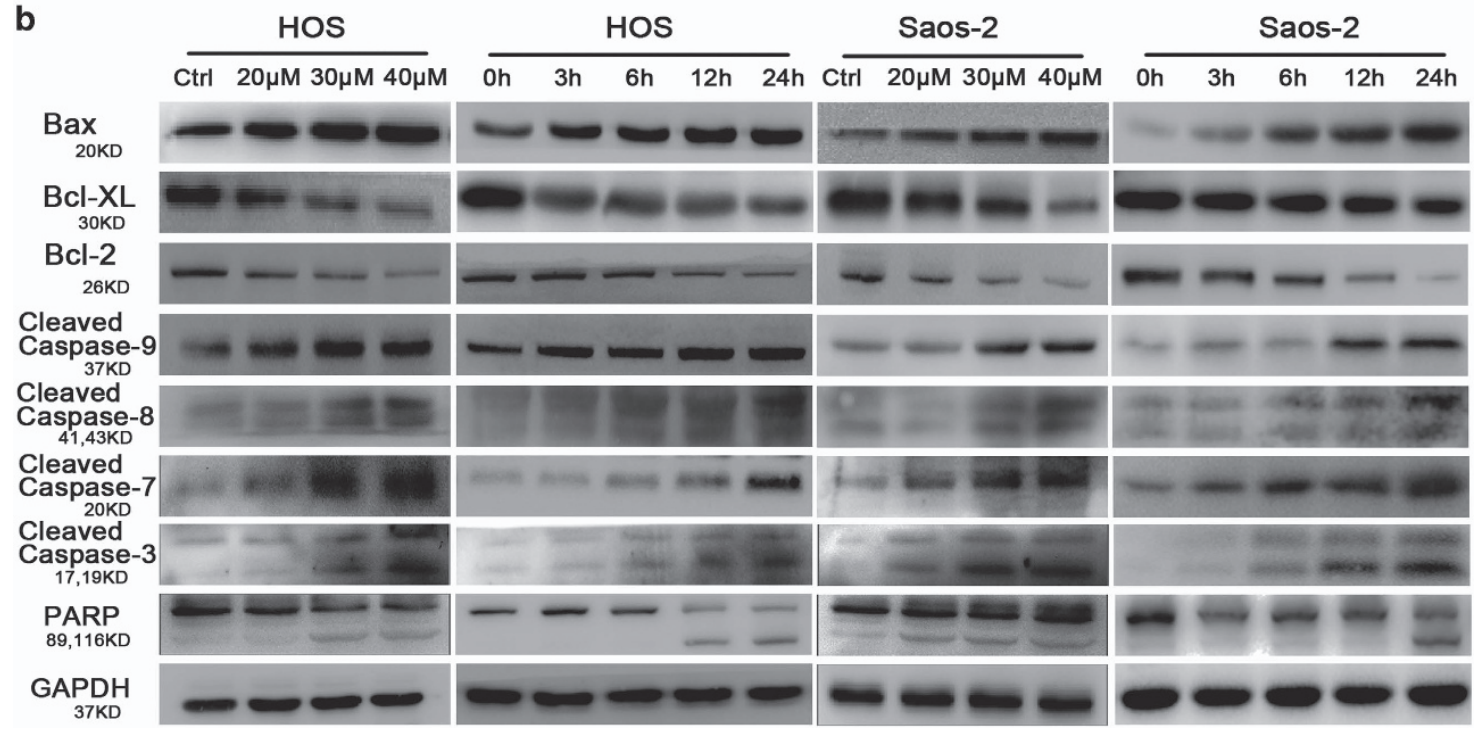

Figure 2 Escin induced the apoptosis of osteosarcoma cells. (a) Hoechst 33258 staining was used to evaluate apoptotic morphology by fluorescence microscopy. The red arrows indicate apoptotic chromatin condensation and DNA fragmentation. Scale bar, $100 \mu \mathrm{m}$. (b) Osteosarcoma cells were exposed to various concentrations of escin for $24 \mathrm{~h}$. The expression of the following apoptosis-related proteins was determined by western blot analysis: cleaved PARP, caspase-3, $-7,-8$, and -9 , and Bcl-2 family members Bcl-2, $\mathrm{Bcl}-\mathrm{xL}$ and Bax

in vivo orthotopic model of osteosarcoma by inoculating osteosarcoma cells (Saos-2 cells transferred with luciferase) into the tibia of nude mice. Tumour size was calculated based on luminescence intensity. Escin at doses of $1.4 \mathrm{mg} / \mathrm{kg}$ and $2.8 \mathrm{mg} / \mathrm{kg}$ caused a decrease in tumour luminescence intensity after 7 days of drug administration, and there was a significant difference between the two groups after 21 days (Figures $6 \mathrm{a}$ and b). X-ray analysis showed that escin minimized osteoclasia during osteosarcoma development (Figure 6c). The tumour-located in the right leg was excised (Figure 6d). The H\&E, Ki-67 staining and terminal deoxynucleotidyl transferase-mediated (d)-UTP nick-end labelling (TUNEL) assays revealed more tumour cell death after escin treatment. The mean optical density was calculated using Image-pro software, and this immunohistochemical analysis confirmed the increased expression of LC3, caspase-3 and p38/MAPK induced by escin (Figure 6e). These results indicated that escin inhibits the growth of osteosarcoma in vivo.

\section{Discussion}

Osteosarcoma is one of the most malignant neoplasms in adolescents. Current therapies incorporate surgery and combination chemotherapy, which cures nearly $70 \%$ of patients. However, the survival of metastatic osteosarcoma patients has remained virtually unchanged over recent decades, with an overall 5-year survival rate of nearly $20 \%{ }^{42}$ Thus, there is an urgent need to discover innovative drugs for the treatment of osteosarcoma. An increasing number of studies have shown that escin has anti-tumour potential against various types of cancer. ${ }^{8,43-45}$ However, the corresponding mechanisms remain to be elucidated. In this study, we confirmed that escin inhibited osteosarcoma growth by inducing apoptosis and autophagy through the ROS/p38 MAPK pathway.

Apoptosis is the main pathway of drug-induced cell death. In this study, we found that escin activated caspase-dependent apoptosis through mitochondrial-mediated pathways, upregulated the expression of the pro-apoptotic protein Bax and 
a
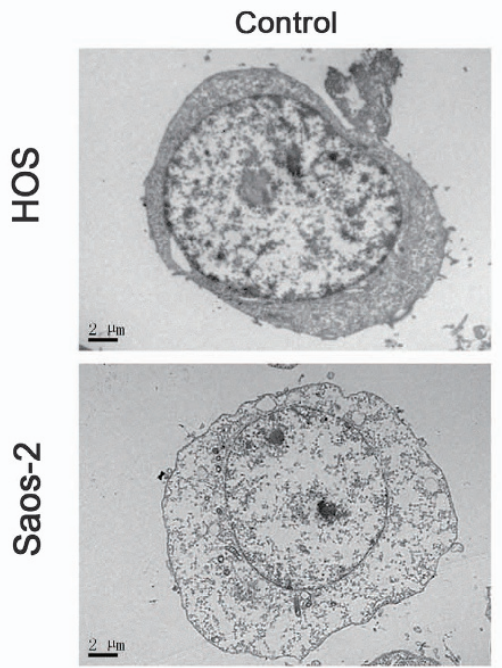
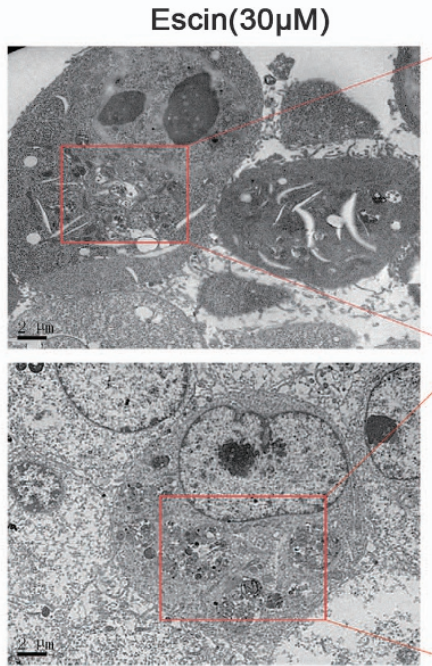
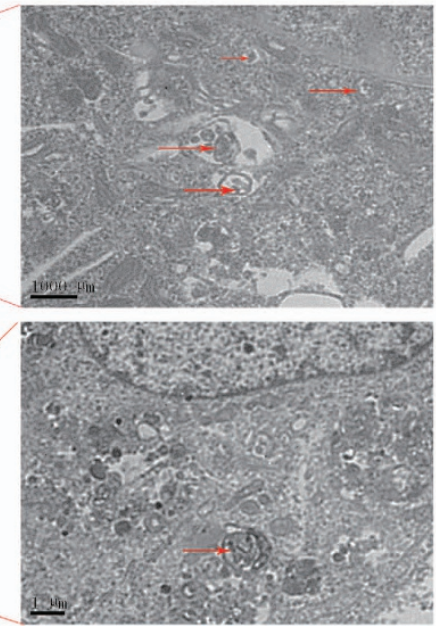

b

HOS

HOS

Saos-2

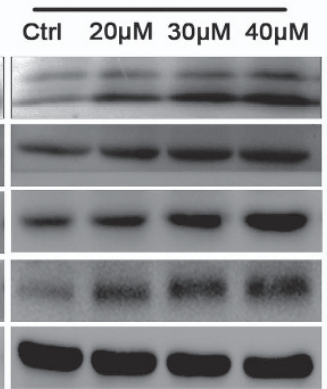

Saos-2

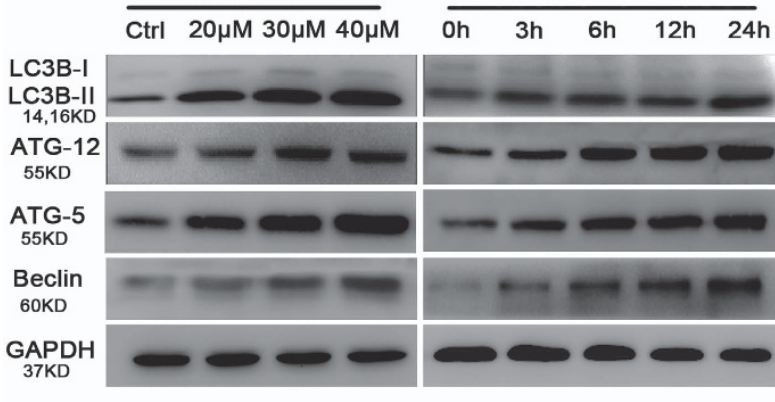

C

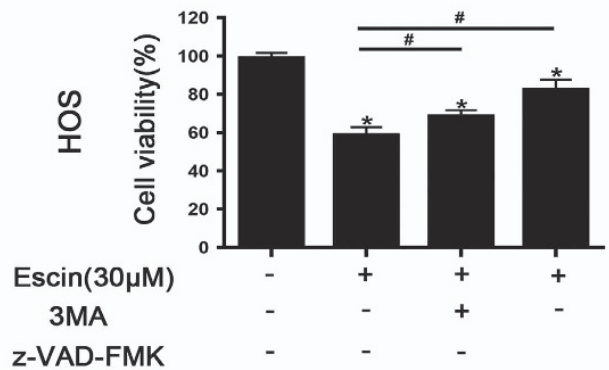

Figure 3 Escin induced the autophagy of osteosarcoma cells. (a) Morphological changes associated with autophagy were observed by transmission electron microscopy. The red arrows indicate autophagosomes. Scale bar, $2 \mu \mathrm{m}$. (b) Osteosarcoma cells were treated with escin at various concentrations for different periods of time. The expression of autophagy-related protein, including LC-3B, Beclin, ATG5 and ATG12, was determined by western blot. (c) Cell viability was measured using an MTS assay. The histogram contains data from three separate experiments. ${ }^{*} P<0.05$ versus control, ${ }^{\#} P<0.05$ versus escin treatment

downregulated the expression of the anti-apoptotic proteins $\mathrm{BCl}-2$ and Bcl-xL. Surprisingly, escin-induced cell death could not be fully reversed by the apoptosis inhibitor Z-VAD-FMK, implying that apoptosis was not the only contributor.

Autophagy is involved in type II programmed cell death, particularly in apoptosis-deficient cells, and can be exploited to suppress tumour growth. ${ }^{46}$ In accordance with previous studies $^{8,47-49}$ that used TEM observation to show apoptotic and autophagic death, our study used TEM observation and western blot analysis to confirm the formation of autophagosomes and the elevated expression of autophagic markers after escin treatment, respectively. Beclin-1 is a pivotal protein in autophagy, and the upregulation of Beclin-1 can lead to autophagy. ${ }^{50,51}$ We found that escin upregulated Beclin-1 expression. While many studies ${ }^{52,53}$ have demonstrated that autophagy functions as a survival mechanism in cancer development, our results showed that escin-induced cell death was moderately diminished by the autophagy inhibitor 3-MA, demonstrating the contribution of autophagy to cell death instead of survival.

To further explore the upstream pathways, we tested the potential ones that might be involved in the process of apoptosis and autophagy. The p38/MAPK pathway was reported to be involved in regulating apoptosis and autophagy. ${ }^{54}$ Recent studies have found that higher p38/ MAPK expression correlates with the increased expression of autophagic markers, such as LC3B and ATG5/ATG12, and apoptotic markers, such as caspase-3 and PARP. ${ }^{21,55,56}$ In the 


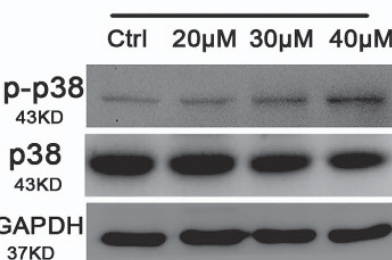

b
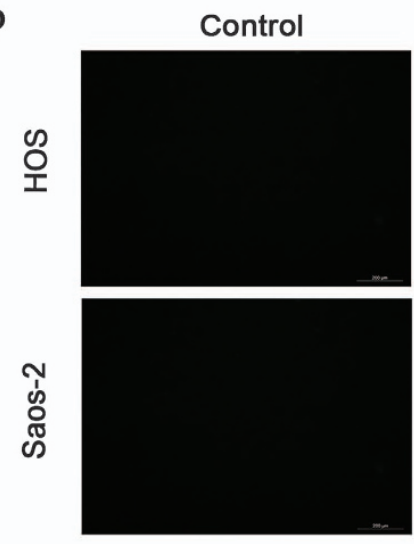

C

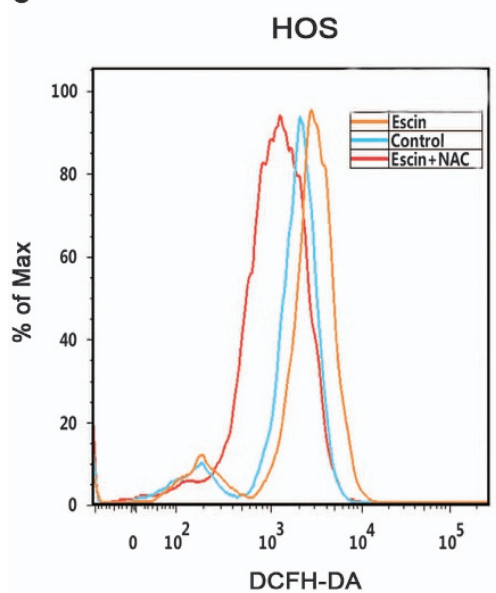

HOS

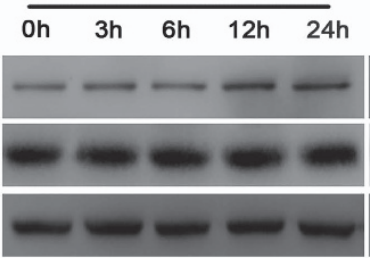

$\operatorname{Escin}(20 \mu \mathrm{M})$
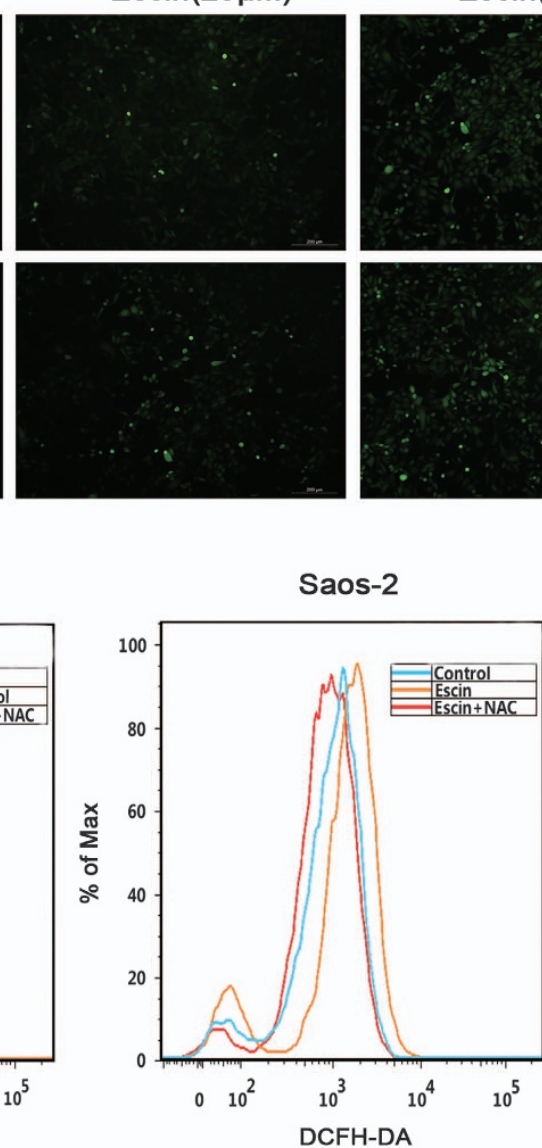

Saos-2

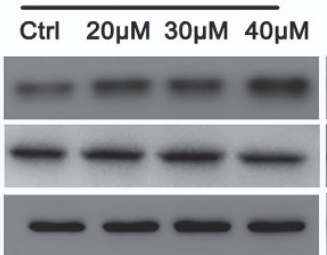

$\operatorname{Escin}(30 \mu \mathrm{M})$
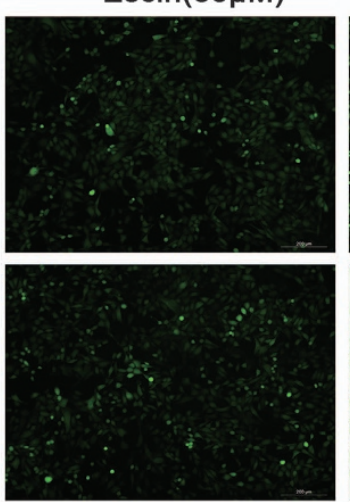

d

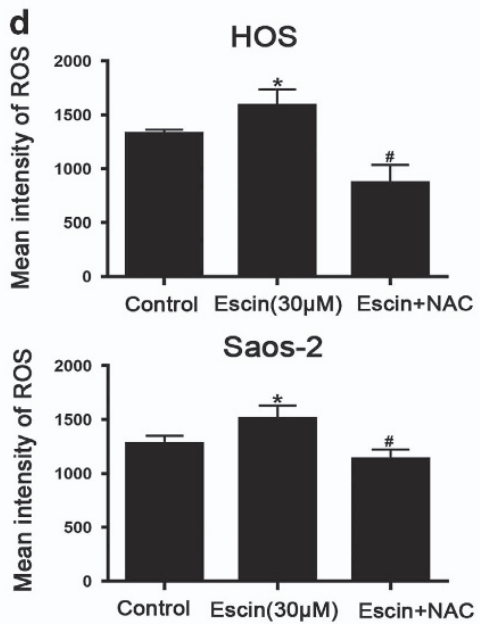

Figure 4 Escin triggered ROS generation and activated p38 MAPK. (a) Cells were exposed to escin at various concentrations for different periods of time. The levels of phospho-p38 MAPK and total p38 MAPK were determined by western blot. (b) Osteosarcoma cells were exposed to escin for $24 \mathrm{~h}$ and then stained with DCFH-DA for $30 \mathrm{~min}$. ROS generation was observed by fluorescence microscopy and representative images are presented. Scale bar, $200 \mu \mathrm{m}$. (c,d) The cells were preincubated with NAC (5 mM) for $1 \mathrm{~h}$ and then treated with escin for $24 \mathrm{~h}$. Intracellular ROS levels were determined by flow cytometry. The histogram shows the intensity of ROS. ${ }^{*} P<0.05$ versus control, ${ }^{\#} P<0.05$ versus escin treatment

present study, escin induced a significant increase in p38 phosphorylation. SB203580, an inhibitor of p38/MAPK phosphorylation, was used to confirm the role of p38/MAPK in escin-induced autophagy and apoptosis. The expression levels of autophagy and apoptosis-related protein markers were decreased upon inhibition of p38/MAPK phosphorylation.

It is well documented that ROS regulate the expression of p38/MAPK ${ }^{57-59}$ In the present study, increased ROS generation was observed after escin treatment. In addition, the ROS scavenger NAC strongly reversed escin-induced apoptosis and autophagy; in this context, NAC was more potent than the inhibitor of p38/MAPK phosphorylation. Taken together, we concluded that escin induced the autophagy and apoptosis of osteosarcoma cells through the ROS/p38 pathway.

It was reported previously that escin treatment resulted in significant tumour inhibition in vivo. ${ }^{60-62}$ Our in vivo study indicated that escin significantly inhibited osteosarcoma growth during the 3-week treatment period. Moreover, immunohistochemical analysis confirmed increased expression of LC3, caspase-3 and p38/MAPK after escin treatment. Furthermore, X-ray analysis showed that osteoclasia induced by osteosarcoma was minimized by escin.

In conclusion, escin can inhibit osteosarcoma cell proliferation by inducing autophagy and apoptosis mediated by the 

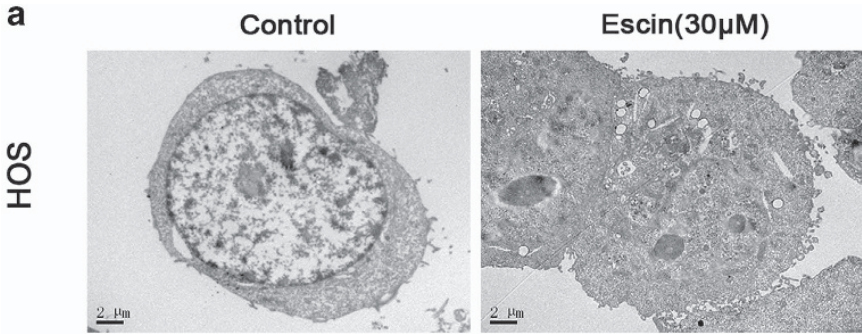

b

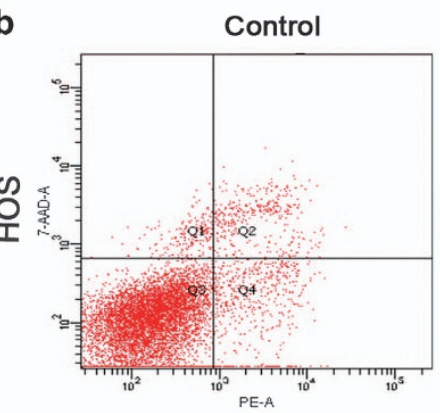

C

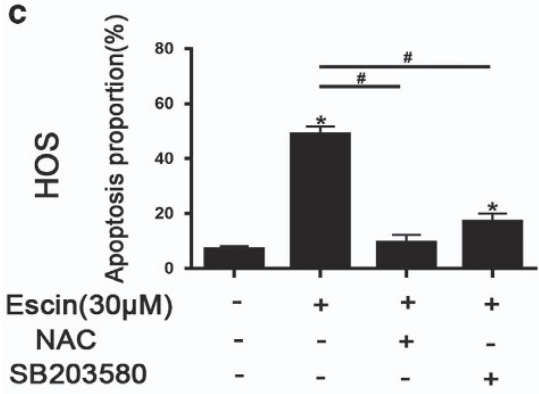

d

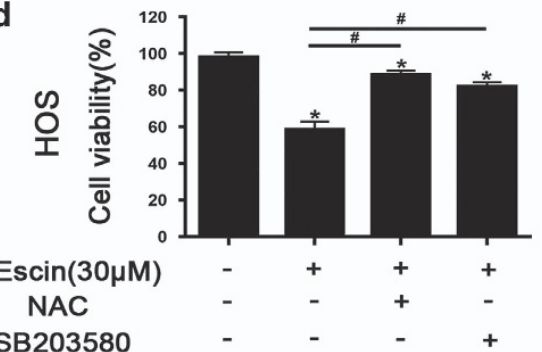

$\operatorname{Escin}(30 \mu \mathrm{M})$

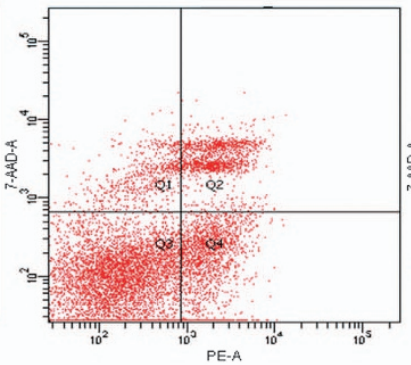

e

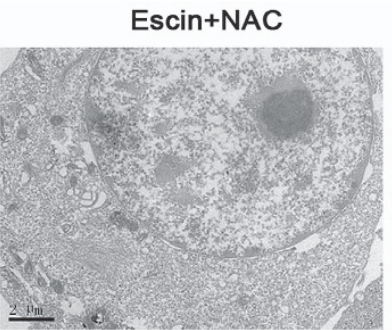

Escin+NAC
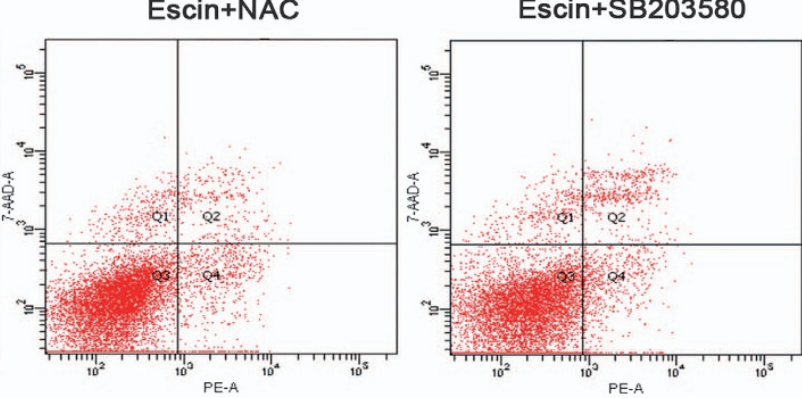

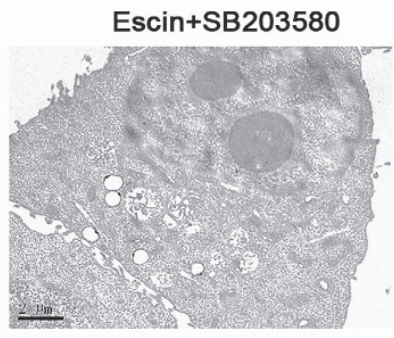

Escin+SB203580

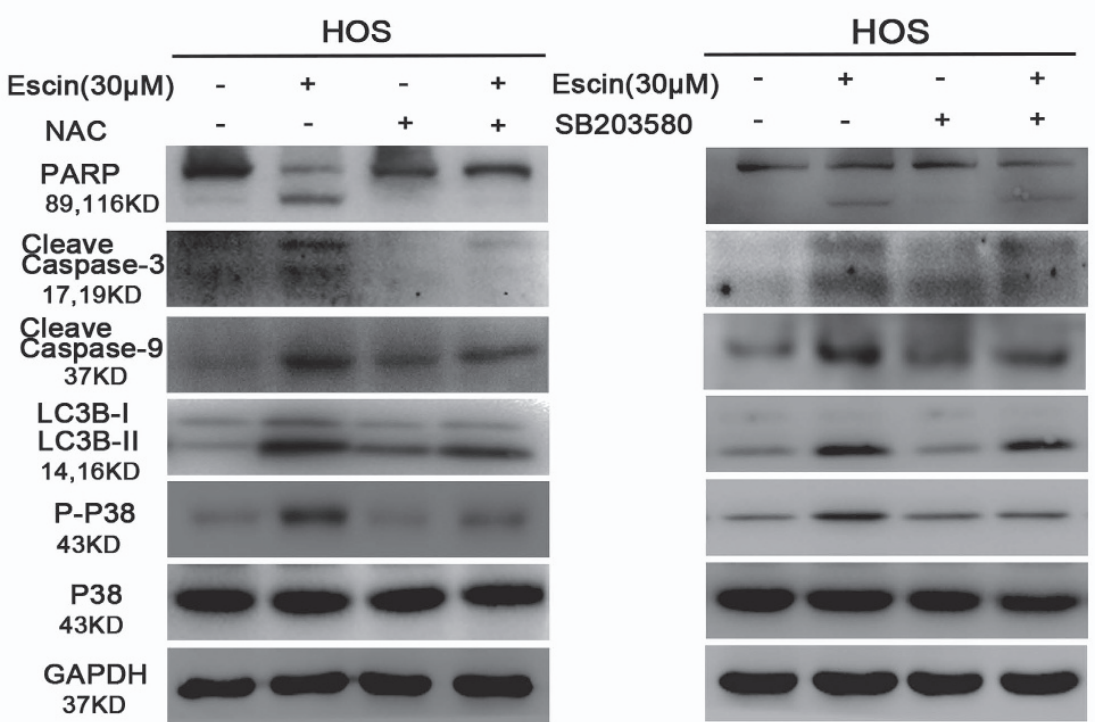

Figure 5 Roles of ROS and p38 MAPK in autophagy and apoptosis. Cells were precultured with the ROS inhibitor NAC (5 mM), p38 MAPK inhibitor SB203580 (10 $\mu$ M), autophagy inhibitor 3-MA (2.5 mM), or the apoptosis inhibitor z-VAD-fmk ( $20 \mu \mathrm{M})$ for $2 \mathrm{~h}$ and then exposed to escin $(30 \mu \mathrm{M})$ for $24 \mathrm{~h}$. (a) Morphological changes in cells exposed to escin and NAC or SB203580 were observed by transmission electron microscopy. Scale bar, $2 \mu \mathrm{m}$. (b,c) The apoptotic proportion was measured by flow cytometry. The histogram includes data from three separate experiments. (d) Cell viability was measured using an MTS assay. The histogram presents data from three separate experiments. (e) The expression levels of LC3B, cleaved PARP, cleaved caspase-3, cleaved caspase-9, and p38 MAPK were analysed by western blotting. ${ }^{*} P<0.05$ versus control, ${ }^{\#} P<0.05$ versus escin treatment

ROS/p38 MAPK signalling pathway (Figure 7). Escin exhibited potent anti-tumour activity in the orthotopic osteosarcoma model. The results of this study provide new insights into the potential efficacy of escin in the treatment of osteosarcoma.

\section{Materials and Methods}

Reagents and antibodies. Escin powder with purity greater than $95 \%$, the p38 MAPK inhibitor SB203580, NAC and 3-Methyladenine (3-MA) were purchased from Sigma-Aldrich (St. Louis, MO, USA). Minimum essential medium (MEM), Eagle's minimum essential medium (EMEM) and McCoy's 5A Medium, RPMI 1640 Medium, fetal bovine serum (FBS), penicillin, streptomycin, PBS and $0.25 \%$ trypsin were purchased from Gibco/BRL (Gaithersburg, MD, USA). The caspase inhibitor (z-VAD-fmk) was obtained from Millipore (Billerica, MA, USA). Antibodies against PARP, caspase-3, caspase-7, caspase-8, caspase-9, Bax, Bcl-2, Bcl-XL, phosphop38 MAPK(Thr180/Tyr182), p38, LC3B, Beclin-1, SQSTM1/p62, ATG5, ATG12 and GAPDH were obtained from Cell Signaling Technology (Beverly, MA, USA).

Cell and cell culture. The human osteosarcoma cell lines MNNG/HOS (CRL-1547TM, ATCC), Saos-2 (HTB-85TM, ATCC), MG-63 (CRL-1427TM, ATCC), U-2OS (HTB-96TM, ATCC), HUVEC (CRL-1730TM, ATCC) were obtained from Cell Bank of Shanghai Institute of Biochemistry and Cell Biology, Chinese Academy of Sciences (Shanghai, China). According to the ATCC instructions, MNNG/HOS cells were cultured in EMEM, with MG-63 in MEM, Saos-2 in McCoy's 5 A medium, 

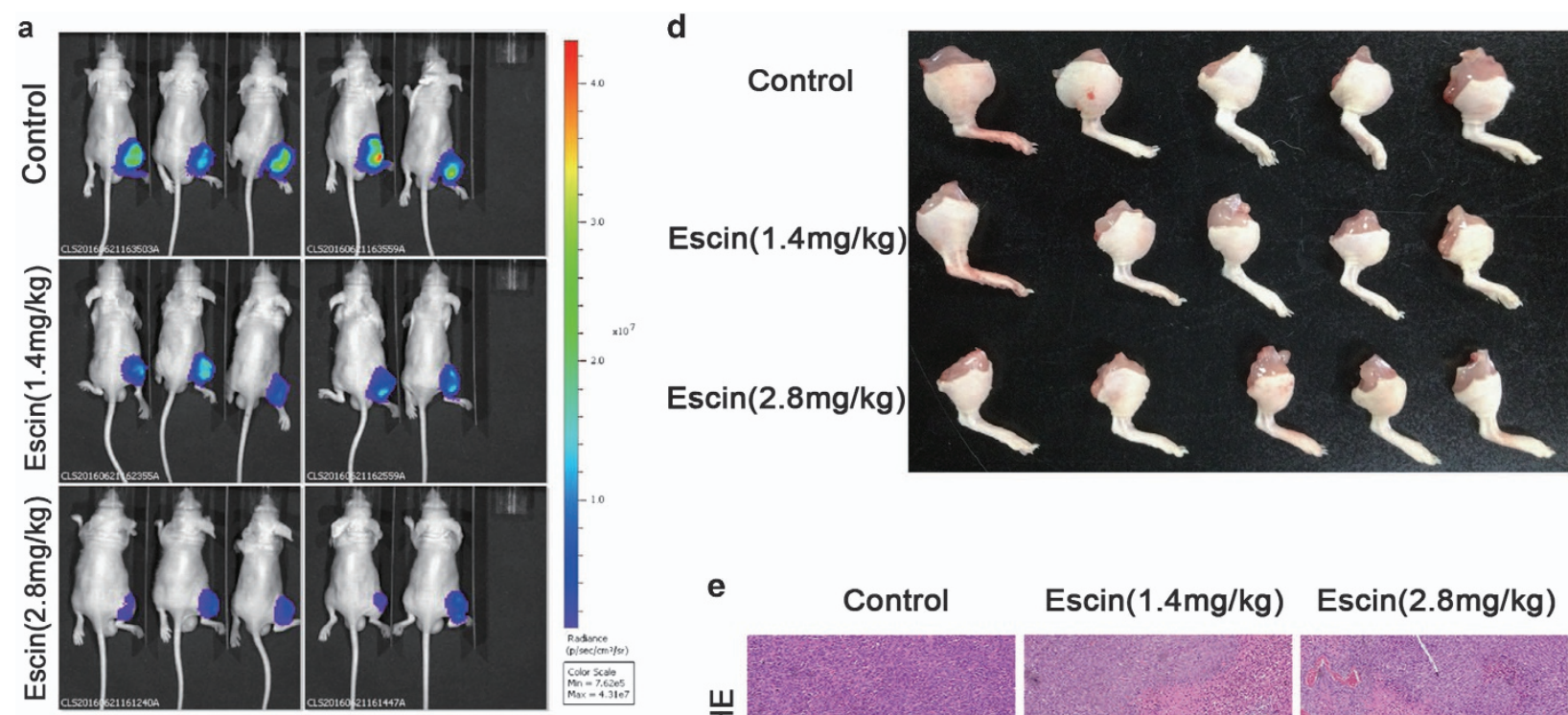

e Control

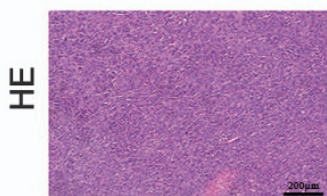

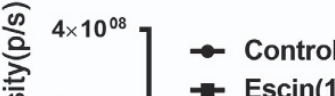

$3 \times 10^{08}-\mathrm{Escin}(1.4 \mathrm{mg} / \mathrm{kg})$

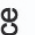

屯

들

气

0

$\pm \operatorname{Escin}(2.8 \mathrm{mg} / \mathrm{kg})$

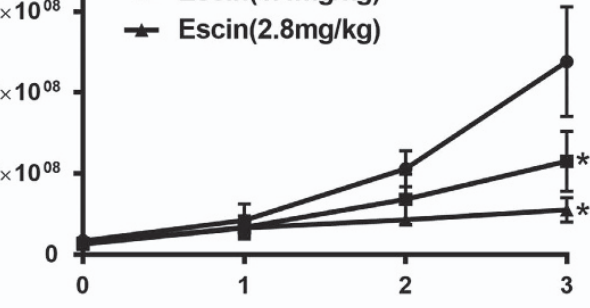

Time(weeks)

\section{Control Escin(1.4mg/kg)Escin $(2.8 \mathrm{mg} / \mathrm{kg})$}

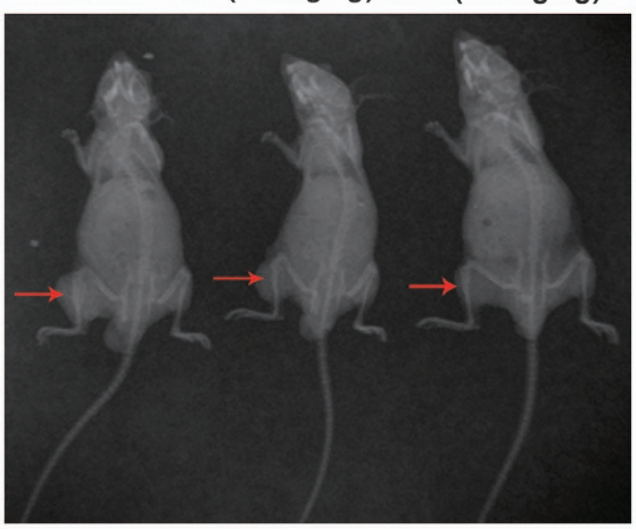

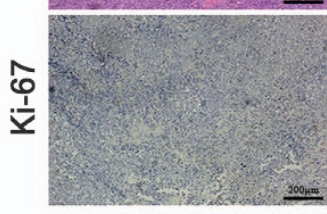

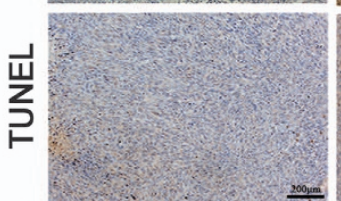

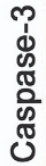
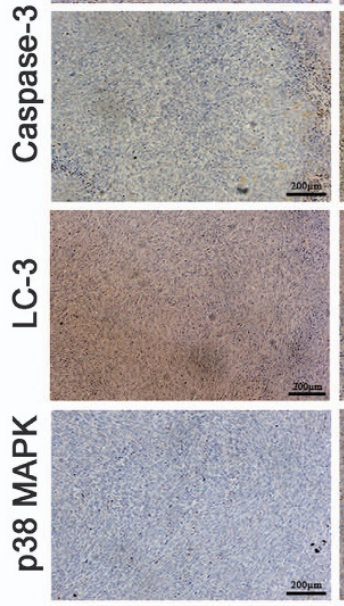

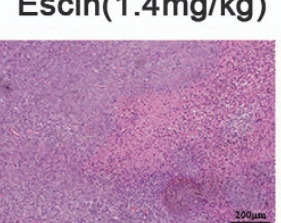

\section{Escin(2.8mg/kg)}
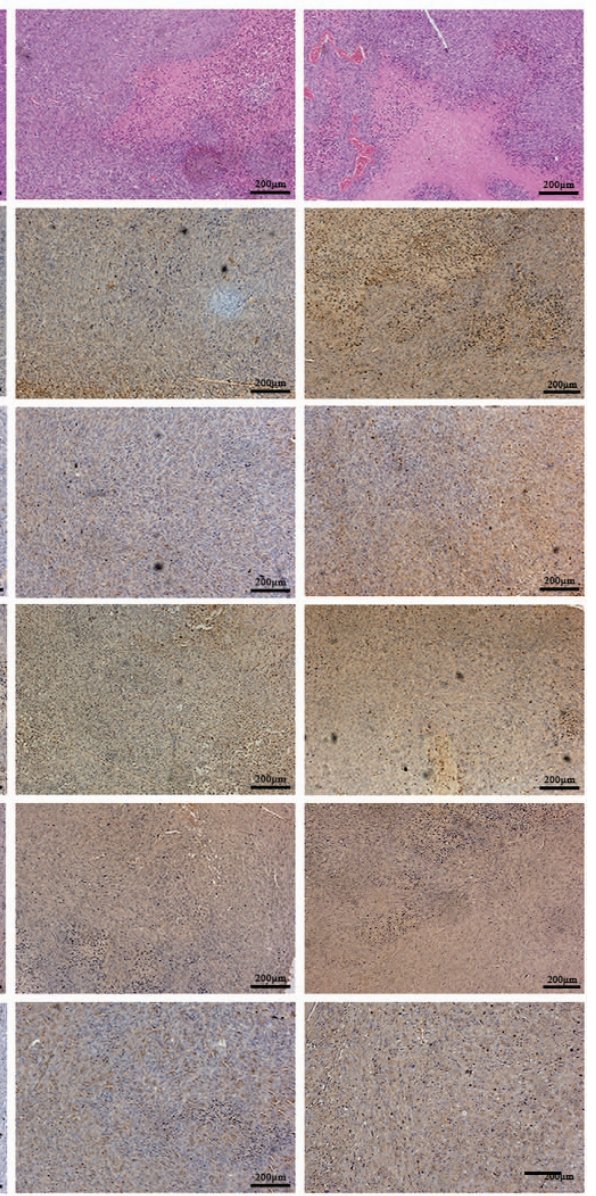

Figure 6 Escin inhibits the growth of human osteosarcoma xenografts in vivo. Saos2-luc cells were inoculated orthotopically in the right tibia of BALB/c-nu mice. After 3 days, the tumour in the tibia was assessed using an in vivo imaging system, and the luminescence intensity was used as an indicator of tumour size. Then, the mice were separated randomly into three groups. The next day, the mice began receiving daily intraperitoneal injections of PBS or escin (1.4 or $2.8 \mathrm{mg} / \mathrm{kg})$. After 21 days of treatment, all mice were killed. (a) The tumour-located in the right leg was excised and imaged. (b) H\&E staining was used to evaluate histology. The apoptotic status of tumour tissues was assessed by TUNEL assays and Ki-67 expression. The levels of cleaved caspase-3, LC3B and phospho-38 MAPK were further examined by immunohistochemistry. Representative images are presented. Scale bar, $200 \mu \mathrm{m}$. (c,d) On the 21 st day of dosing, the tumour in the tibia was assessed using an in vivo imaging system, and luciferase intensity was calculated using the in vivo imaging software. (e) The mice underwent X-ray analysis to assess osteoclasia in the tibia. The mice are shown in the following order of treatments: PBS, escin $(1.4 \mathrm{mg} / \mathrm{kg})$ and escin $(2.8 \mathrm{mg} / \mathrm{kg})$. The red arrows indicate osteoclasia. ${ }^{*} P<0.05$ compared with control 


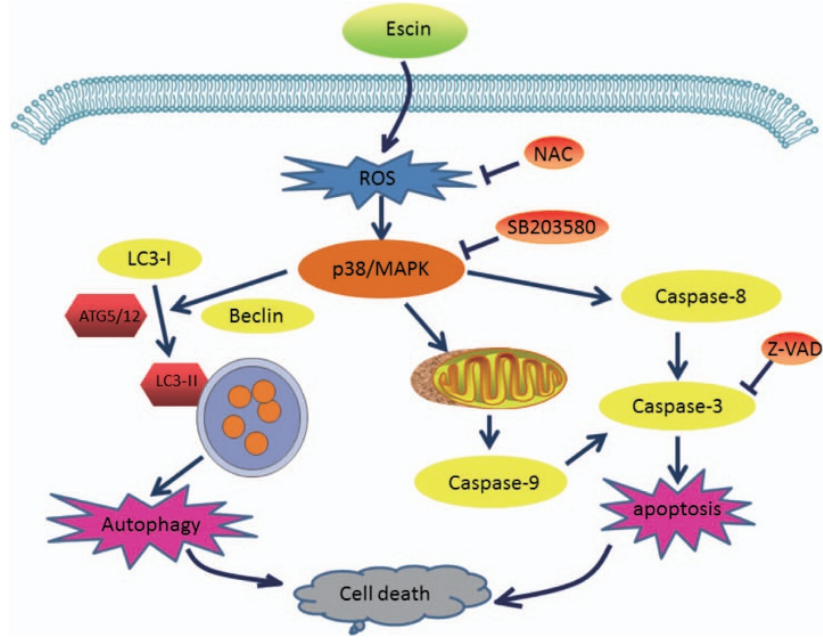

Figure 7 A brief diagram of the effects of escin on osteosarcoma cells

U-2OS in RPMI 1640 and HUVECs in F-12K medium. All media included 10\% FBS $100 \mathrm{U} / \mathrm{ml}$ penicillin and $100 \mu \mathrm{g} / \mathrm{ml}$ streptomycin. The cells were incubated at $37^{\circ} \mathrm{C}$ in a humidified incubator with $5 \% \mathrm{CO}_{2}$.

Cell viability assay. The inhibitory effect of escin on osteosarcoma cells was detected using an MTS kit (cellTiter 96 AQueous One solution Cell Proliferation Assay, Promega, Madison, WI, USA). According to the manufacturer's instruction, cells were cultured in 96 -well plates at approximately $4-5 \times 10^{3}$ cells per well. When the cells were adherent to the bottom of the cell, the cells were treated with various concentrations of escin $(0-50 \mu \mathrm{M})$ for different periods of time $(0-48 \mathrm{~h})$. Then MTS was added and incubated for $2-4 \mathrm{~h}$ at $37^{\circ} \mathrm{C}$. The absorbance at $490 \mathrm{~nm}$ was measured using a MR7000 microplate reader (Dynatech, NV, USA). The data were calculated from the mean of six replicates, each experiment was conducted in triplicate.

Morphological apoptosis. Morphological changes of apoptosis were measured by fluorescence microscopy using Hoechst 33258 staining. Briefly, cells were treated with different concentrations of escin for $24 \mathrm{~h}$ and then exposed to Hoechst 33258 for approximately $10 \mathrm{~min}$. Then, the cells were washed with PBS twice. Fluorescence microscopy (Olympus, Tokyo, Japan) was used to visualize morphological changes, such as chromatin condensation.

Transmission electron microscopy detection. TEM was used to observe the cell ultra-structure. Changes regarding apoptotic body and nuclear condensation indicated apoptosis, and the formation of autophagosome indicated autophagy. Cells treated with escin were first fixed with $2.5 \%$ glutaraldehyde and subsequently fixed with $1 \%$ osmium tetroxide. Cells were embedded in Epon after dehydrated with different concentrations of alcohol. Ultrathin sections $(0.5 \mu \mathrm{m})$ were generated for observation under a transmission electron microscope.

Apoptosis measurement. Apoptosis was measured using the reagent Annexin V-PE/7-AAD kit (BD Biosciences, San Diego, CA, USA). Cells were incubated in six-well plates at approximately $2-3 \times 10^{5}$ cells per well and treated with different concentrations of escin for $24 \mathrm{~h}$. Then, the cells were incubated with Annexin V-PE/7-AAD kit for approximately $15 \mathrm{~min}$ at room temperature in the dark. After washing with PBS twice, the cells were resuspended in $500 \mu \mathrm{l}$ of PBS. Then, samples were evaluated using a flow cytometer (FACSCalibur, BD, San Jose, CA, USA).

Measurement of ROS. ROS were detected by ROS assay kits (Beyotime Biotechnologies, Jiangsu, China) containing DCFH-DA. According to the manufacturer's introduction, cells treated with escin were collected at a concentration of $1-2 \times 10^{6} / \mathrm{ml}$. Then, the cells were administered DCFH-DA $(10 \mu \mathrm{M})$ and incubated at $37^{\circ} \mathrm{C}$ for $20 \mathrm{~min}$. Every $3-5 \mathrm{~min}$, the solution was mixed by inversion. Then, ROS generation was evaluated using a fluorescence microscope (Olympus) and a flow cytometer (FACSCalibur, BD).
Western blot analysis. Cells were treated with different concentration of escin $(0-40 \mu \mathrm{M})$ for $24 \mathrm{~h}$. Then, the cells were collected and lysed with RIPA lysis buffer, which included a protease inhibitor cocktail (Sigma-Aldrich). The lysing process lasted for $30 \mathrm{~min}$ on ice, and the solution was vortexed every $10 \mathrm{~min}$. Cell lysates were centrifuged at $13000 \times g$ for $15 \mathrm{~min}$ at $4{ }^{\circ} \mathrm{C}$. Then, the supernatant was collected, and the total amount of protein was quantified using a BCA protein assay kit (Pierce, Waltham, MA, USA). Equal protein was separated by $8-12 \%$ SDS-PAGE at $80 \mathrm{~V}$ for $1.5 \mathrm{~h}$. Then, the proteins were transferred onto $2.2 \mu \mathrm{m}$ polyvinylidene fluoride membranes (Millipore) at $250 \mathrm{~mA}$ for $2 \mathrm{~h}$ in a humid atmosphere. The membranes were blocked with $5 \%$ bovine serum albumin (SigmaAldrich) solution for $1 \mathrm{~h}$ at room temperature. Then, the membranes were incubated with the primary antibody (Cell Signaling Technology) at the recommended dilution at $4{ }^{\circ} \mathrm{C}$ overnight. After being washed with TBST for $30 \mathrm{~min}$, the membranes were incubated with horseradish peroxidase (HRP)-conjugated secondary antibodies (Cell signaling technology) at room temperature for $1 \mathrm{~h}$. The target bands were developed by enhanced chemiluminescence kit (Millipore).

Xenograft orthotopic model. Male BALB/c-nu mice (4 weeks old) were obtained from Shanghai Laboratory Animal Center of Chinese Academy of Sciences. The mice were maintained under specific pathogen-free conditions. Saos2 cells were transfected with luciferase (Saos-2-luc) for in vivo imaging. Saos-2-luc cells $\left(5 \times 10^{6}\right)$ suspended in $50 \mu$ l of PBS were injected into the right tibia of each mouse. On the third day, the luminescence intensity was measured using an in vivo bioluminescence imaging system. When the luminescence intensity reached $1 \times 10^{6}$ $\mathrm{p} / \mathrm{s}$, mice were randomly divided into three groups (five mice per group). Mice with a very low or high luminescence signal were killed. Then, the mice received daily intraperitoneal injections of $100 \mu \mathrm{l}$ of PBS, $1.4 \mathrm{mg} / \mathrm{kg}$ of escin or $2.8 \mathrm{mg} / \mathrm{kg}$ of escin. The luminescence intensity was measured weekly. After 21 days of dosing, all mice were killed. The tumours were excised and fixed in 10\% formalin for further analysis. All treatments were approved by the Research Ethics Committee of the Second Affiliated Hospital of Zhejiang University School of Medicine, China.

Tumour histology. The excised tumour were fixed with $4 \%$ formalin, dehydrated in a graded alcohol series and embedded in paraffin. Tumour tissue was cut into serial sections $(3 \mu \mathrm{m})$ that were stained with $\mathrm{H} \& \mathrm{E}$ after deparaffinization for histological analysis.

In situ TUNEL staining. A TUNEL kit (Roche Diagnostics, Mannheim, Germany) was used to evaluate apoptosis. Briefly, after deparaffinization and hydration, the sections were incubated with proteinase $\mathrm{K}(20 \mu \mathrm{g} / \mathrm{ml})$ for $15 \mathrm{~min}$ at room temperature. After permeabilization, slides were incubated with the TUNEL reaction mixture. HRP-conjugated Fab fragments were used to detect labelled DNA strand breaks.

Immunohistochemistry analysis. For immunohistochemical analysis, sections were deparaffinized in xylene and hydrated with gradient increased alcohol. To block endogenous peroxidase activity, the sections were treated with $3 \%$ $\mathrm{H}_{2} \mathrm{O}_{2}$ for 15 min. Next, sections were immersed in boiling sodium citrate buffer $(\mathrm{pH}$ 6.0) for $10 \mathrm{~min}$. Then, the slides were treated with $10 \%$ goat serum for $15 \mathrm{~min}$ at room temperature and incubated with antibodies against cleaved caspase 3, Ki-67, LC3-B, and phospho-p38 MAPK at $4{ }^{\circ} \mathrm{C}$ overnight. After washing five times with PBS, the slides were incubated with biotin-labelled secondary antibody at $37^{\circ} \mathrm{C}$ for 30 min. Immunoreactivity was detected by SABC method. A DP70 CCD camera (Olympus) couple with an AX-70 microscope (Olympus) was used to record images. Image-pro-plus (version. 6.0, Media Cybernetics) was used for digital image analysis. The measure parameters contained mean density, total area and IOD. The optical density was calibrated and the area of interest assigned value for hue, $0-30$; saturation, $0-255$; intensity, $0-230$. Then the image was transformed into a greyscale image, and values were measured.

In vivo bioluminescence assay. For in vivo imaging, $200 \mu \mathrm{l}$ of luciferin $(15 \mathrm{mg} / \mathrm{ml})$ was injected intraperitoneally into the mice. After approximately $10 \mathrm{~min}$, the mice were anaesthetized with isoflurane. In vivo imaging was performed using an IVIS 200 imaging system, and the results were analysed with Living Image Software (Version 3.0.4, Xenogen, Hopkinton, MA, USA). Total flux of the region of interest was measured in photons $(\mathrm{p}) / \mathrm{s}$ for each mouse.

X-ray. X-rays were utilized to identify the tumour- associated osteoclasia in the tibia. The mice with an orthotopic tumour underwent $\mathrm{X}$-ray analysis. $\mathrm{X}$-rays were 
taken at $40 \mathrm{kV}$ and $50 \mathrm{~mA}$ using a high-frequency mobile $\mathrm{C}$ arm X-ray machine (PLX7000).

Statistical analysis. The quantitative data were described as the mean \pm S.D. The data differences were calculated using a one-way ANOVA and Student's t-test. All statistics were analysed with the SPSS software (21.0, SPSS, Chicago, IL, USA). Statistical significance was identified as $P<0.05$.

\section{Conflict of Interest}

The authors declare no conflict of interest.

Acknowledgements. This research was supported by grants from the Nationa Natural Science Foundation of China (No. 81472504, Nos 81401822 and 81572177 ), Science and Technology Foundation of Zhejiang Province (2016C33151), Medical Science and Technology Project of Zhejiang Province of China (2016146428, 2016KYA096 and 2017KY071) and Natural Science Funds of Zhejiang Province (Y17H160033, LQ14H060002 and LY14H060004).

\section{Publisher's Note}

Springer Nature remains neutral with regard to jurisdictional claims in published maps and institutional affiliations.

1. Kansara M, Teng MW, Smyth MJ, Thomas DM. Translational biology of osteosarcoma. Nat Rev Cancer 2014; 14: 722-735.

2. Arndt CA, Rose PS, Folpe AL, Laack NN. Common musculoskeletal tumors of childhood and adolescence. Mayo Clin Proc 2012; 87: 475-487.

3. Vos HI, Coenen MJ, Guchelaar HJ, Te Loo DM. The role of pharmacogenetics in the treatment of osteosarcoma. Drug Discov Today 2016; 21: 1775-1786.

4. Yan GN, Lv YF, Guo QN. Advances in osteosarcoma stem cell research and opportunities for novel therapeutic targets. Cancer lett 2016; 370: 268-274.

5. Gill J, Ahluwalia MK, Geller D, Gorlick R. New targets and approaches in osteosarcoma. Pharmacol therapeut 2013; 137: 89-99.

6. Zhang K, Jiang Z, Ning X, Yu X, Xu J, Buzzacott $P$ et al. Endothelia-targeting protection by escin in decompression sickness rats. Sci Rep 2017; 7: 41288.

7. Domanski D, Zegrocka-Stendel O, Perzanowska A, Dutkiewicz M, Kowalewska M, Grabowska I et al. Molecular mechanism for cellular response to beta-escin and its therapeutic implications. PloS one 2016; 11: e0164365.

8. Harford-Wright E, Bidere N, Gavard J. beta-escin selectively targets the glioblastomainitiating cell population and reduces cell viability. Oncotarget 2016; 7: 66865-66879.

9. Tan SM, Li F, Rajendran P, Kumar AP, Hui KM, Sethi G. Identification of beta-escin as a novel inhibitor of signal transducer and activator of transcription 3/Janus-activated kinase 2 signaling pathway that suppresses proliferation and induces apoptosis in human hepatocellular carcinoma cells. J pharmacol exp therapeut 2010; 334: 285-293.

10. Mojzisova G, Kello M, Pilatova M, Tomeckova V, Vaskova J, Vasko L et al. Antiproliferative effect of beta-escin - an in vitro study. Acta biochim Pol 2016; 63: 79-87.

11. Ravegnini G, Sammarini G, Nannini M, Pantaleo MA, Biasco G, Hrelia P et al. Gastrointestinal stromal tumors (GIST): facing cell death between autophagy and apoptosis. Autophagy 2017; 13: 452-463 1-12.

12. Xu Y, Chu L, Yuan S, Yang Y, Yang Y, Xu B et al. RGD-modified oncolytic adenovirusharboring shPKM2 exhibits a potent cytotoxic effect in pancreatic cancer via autophagy inhibition and apoptosis promotion. Cell death dis 2017; 8: e2835.

13. Kondo $Y$, Kanzawa T, Sawaya R, Kondo $S$. The role of autophagy in cancer development and response to therapy. Nat Rev Cancer 2005; 5: 726-734.

14. Marino G, Niso-Santano M, Baehrecke EH, Kroemer G. Self-consumption: the interplay of autophagy and apoptosis. Nat Rev Mol Cell Biol 2014; 15: 81-94.

15. Zhang Y, Shen K, Bai Y, Lv X, Huang R, Zhang W et al. Mir143-BBC3 cascade reduces microglial survival via interplay between apoptosis and autophagy: implications for methamphetamine-mediated neurotoxicity. Autophagy 2016; 12: 1538-1559.

16. Tanaka S, Hikita H, Tatsumi T, Sakamori R, Nozaki Y, Sakane S et al. Rubicon inhibits autophagy and accelerates hepatocyte apoptosis and lipid accumulation in nonalcoholic fatty liver disease in mice. Hepatology 2016; 64: 1994-2014.

17. Cerezo M, Rocchi S. New anti-cancer molecules targeting HSPA5/BIP to induce endoplasmic reticulum stress, autophagy and apoptosis. Autophagy 2017; 13: 216-217.

18. Guo JY, Xia B, White E. Autophagy-mediated tumor promotion. Cell 2013; 155: 1216-1219.

19. Pei H, Zhang J, Nie J, Ding N, Hu W, Hua J et al. RAC2-P38 MAPK-dependent NADPH oxidase activity is associated with the resistance of quiescent cells to ionizing radiation. Cell cycle 2017; 16: 113-122.

20. Kim KY, Park KI, Kim SH, Yu SN, Park SG, Kim YW et al. Inhibition of autophagy promotes salinomycin-induced apoptosis via reactive oxygen species-mediated PI3K/AKT/mTOR and ERK/p38 MAPK-dependent signaling in human prostate cancer cells. Int J Mol Sci 2017; 18: 1088.
21. El Hasasna $\mathrm{H}$, Athamneh $\mathrm{K}$, Al Samri H, Karuvantevida N, Al Dhaheri $Y$, Hisaindee $\mathrm{S}$ et al. Rhus coriaria induces senescence and autophagic cell death in breast cancer cells through a mechanism involving p38 and ERK1/2 activation. Sci Rep 2015; 5: 13013.

22. Hart PC, Mao M, de Abreu AL, Ansenberger-Fricano K, Ekoue DN, Ganini D et al. MnSOD upregulation sustains the Warburg effect via mitochondrial ROS and AMPK-dependent signalling in cancer. Nat commun 2015; 6: 6053.

23. Park H, Noh AL, Kang JH, Sim JS, Lee DS, Yim M. Peroxiredoxin II negatively regulates lipopolysaccharide-induced osteoclast formation and bone loss via JNK and STAT3. Antioxid Redox Signal 2015; 22: 63-77.

24. Xie D, Wu X, Lan L, Shangguan F, Lin X, Chen F et al. Downregulation of TFAM inhibits the tumorigenesis of non-small cell lung cancer by activating ROS-mediated JNK/p38MAPK signaling and reducing cellular bioenergetics. Oncotarget 2016; 7: 11609-11624.

25. Raj L, Ide T, Gurkar AU, Foley M, Schenone M, Li X et al. Corrigendum: selective killing of cancer cells by a small molecule targeting the stress response to ROS. Nature 2015; 526: 596.

26. Sabharwal SS, Schumacker PT. Mitochondrial ROS in cancer: initiators, amplifiers or an Achilles' heel? Nat Rev Cancer 2014; 14: 709-721.

27. Scherz-Shouval R, Elazar Z. Regulation of autophagy by ROS: physiology and pathology. Trends Biochem Sci 2011; 36: 30-38.

28. Anozie UC, Dalhaimer P. Molecular links among non-biodegradable nanoparticles, reactive oxygen species, and autophagy. Adv Drug Deliv Rev 2017 (doi:10.1016/iaddr.2017.01.001).

29. Kalai Selvi S, Vinoth A, Varadharajan T, Weng CF, Vijaya Padma V. Neferine augments therapeutic efficacy of cisplatin through ROS- mediated non-canonical autophagy in human lung adenocarcinoma (A549 cells). Food chem toxicol 2017; 103: 28-40.

30. Wang XH, Xu B, Liu JT, Cui JR. Effect of beta-escin sodium on endothelial cells proliferation, migration and apoptosis. Vascul Pharmacol 2008; 49: 158-165.

31. Hasei J, Sasaki T, Tazawa H, Osaki S, Yamakawa Y, Kunisada T et al. Dual programmed cell death pathways induced by p53 transactivation overcome resistance to oncolytic adenovirus in human osteosarcoma cells. Mol cancer therapeut 2013; 12: 314-325.

32. Huang G, Mills L, Worth LL. Expression of human glutathione S-transferase P1 mediates the chemosensitivity of osteosarcoma cells. Mol cancer therapeut 2007; 6: 1610-1619.

33. Jing Z, Fei W, Zhou J, Zhang L, Chen L, Zhang X et al. Salvianolic acid B, a novel autophagy inducer, exerts antitumor activity as a single agent in colorectal cancer cells. Oncotarget 2016; 7: 61509-61519.

34. Wu J, Ding Y, Chen $\mathrm{CH}$, Zhou Z, Ding $\mathrm{C}$, Chen $\mathrm{H}$ et al. A new oridonin analog suppresses triple-negative breast cancer cells and tumor growth via the induction of death receptor 5 . Cancer lett 2016; 380: 393-402.

35. Hahm ER, Singh SV. Honokiol causes G0-G1 phase cell cycle arrest in human prostate cancer cells in association with suppression of retinoblastoma protein level/phosphorylation and inhibition of E2F1 transcriptional activity. Mol cancer therapeut 2007; 6: 2686-2695.

36. Czabotar PE, Lessene G, Strasser A, Adams JM. Control of apoptosis by the BCL-2 protein family: implications for physiology and therapy. Nat Rev Mol Cell Biol 2014; 15: 49-63.

37. Wang X, Qi H, Wang Q, Zhu Y, Wang X, Jin M et al. FGFR3/fibroblast growth factor receptor 3 inhibits autophagy through decreasing the ATG12-ATG5 conjugate, leading to the delay of cartilage development in achondroplasia. Autophagy 2015; 11: 1998-2013.

38. Fan X, Han S, Yan D, Gao Y, Wei Y, Liu X et al. Foot-and-mouth disease virus infection suppresses autophagy and NF-small ka, CyrillicB antiviral responses via degradation of ATG5-ATG12 by 3Cpro. Cell death Dis 2017; 8: e2561.

39. Bourke LT, McDonnell T, McCormick J, Pericleous C, Ripoll VM, Giles I et al. Antiphospholipid antibodies enhance rat neonatal cardiomyocyte apoptosis in an in vitro hypoxia/reoxygenation injury model via p38 MAPK. Cell death Dis 2017; 8: e2549.

40. Radogna F, Cerella C, Gaigneaux A, Christov C, Dicato M, Diederich M. Cell type-dependent ROS and mitophagy response leads to apoptosis or necroptosis in neuroblastoma. Oncogene 2016; 35: 3839-3853.

41. Zhang J, Kim J, Alexander A, Cai S, Tripathi DN, Dere R et al. A tuberous sclerosis complex signalling node at the peroxisome regulates mTORC1 and autophagy in response to ROS. Nat cell biol 2013; 15: 1186-1196.

42. Meyers PA, Healey JH, Chou AJ, Wexler LH, Merola PR, Morris CD et al. Addition of pamidronate to chemotherapy for the treatment of osteosarcoma. Cancer 2011; 117: $1736-1744$.

43. Huang GL, Shen DY, Cai CF, Zhang QY, Ren HY, Chen QX. beta-escin reverses multidrug resistance through inhibition of the GSK3beta/beta-catenin pathway in cholangiocarcinoma. World j gastroenterol 2015; 21: 1148-1157.

44. Mei JY, Zhang MJ, Wang YY, Liu YH. The positive clinical therapeutically effects of Escin on advanced thyroid cancer. Cancer Med 2017; 6: 937-943.

45. Yuan SY, Cheng CL, Wang SS, Ho HC, Chiu KY, Chen CS et al. Escin induces apoptosis in human renal cancer cells through G2/M arrest and reactive oxygen species-modulated mitochondrial pathways. Oncol rep 2017; 37: 1002-1010.

46. Kim M, Jung JY, Choi S, Lee H, Morales LD, Koh JT et al. GFRA1 promotes cisplatin-induced chemoresistance in osteosarcoma by inducing autophagy. Autophagy 2017; 13: 149-168.

47. Yao Z, Xie F, Li M, Liang Z, Xu W, Yang J et al. Oridonin induces autophagy via inhibition of glucose metabolism in p53-mutated colorectal cancer cells. Cell death dis 2017; 8: e2633.

48. Guney G, Kutlu HM, Iscan A. The apoptotic effects of escin in the H-Ras transformed 5RP7 cell line. Phytother res 2013; 27: 900-905.

49. Selvakumar GP, Manivasagam T, Rekha KR, Jayaraj RL, Elangovan N. Escin, a novel triterpene, mitigates chronic MPTP/p-induced dopaminergic toxicity by attenuating mitochondrial dysfunction, oxidative stress, and apoptosis. J Mol Neurosci 2015; 55: 184-197. 
50. Wrighton KH. Autophagy: kinase crosstalk through beclin 1. Nat Rev Mol Cell Biol 2013; 14 : 402-403.

51. Wei Y, Zou Z, Becker N, Anderson M, Sumpter R, Xiao G et al. EGFR-mediated Beclin 1 phosphorylation in autophagy suppression, tumor progression, and tumor chemoresistance. Cell 2013; 154: 1269-1284.

52. Mauro $\mathrm{C}$, Silvia $\mathrm{C}$. Autophagy inhibition and mitochondrial remodeling join forces to amplify apoptosis in activation-induced cell death. Autophagy 2016; 12: 2496-2497.

53. Pei J, Deng J, Ye Z, Wang J, Gou H, Liu W et al. Absence of autophagy promotes apoptosis by modulating the ROS-dependent RLR signaling pathway in classical swine fever virusinfected cells. Autophagy 2016; 12: 1738-1758.

54. Jiang Q, Li F, Shi K, Wu P, An J, Yang Y et al. Involvement of p38 in signal switching from autophagy to apoptosis via the PERK/elF2alpha/ATF4 axis in selenite-treated NB4 cells. Cell death dis 2014; 5: e1270.

55. Wang Y, Wang JW, Xiao X, Shan Y, Xue B, Jiang G et al. Piperlongumine induces autophagy by targeting p38 signaling. Cell death Dis 2013; 4: e824.

56. Kamel WA, Sugihara E, Nobusue H, Yamaguchi-Iwai S, Onishi N, Maki K et al. Simvastatininduced apoptosis in osteosarcoma cells: a key role of RhoA-AMPK/p38 MAPK signaling in antitumor activity. Mol cancer therapeut 2017; 16: 182-192.

57. Zhang L, Zhang Z, Chen F, Chen Y, Lin Y, Wang J. Aromatic heterocyclic esters of podophyllotoxin exert anti-MDR activity in human leukemia K562/ADR cells via ROS/MAPK signaling pathways. Eur J Med Chem 2016; 123: 226-235.

58. Jian KL, Zhang C, Shang ZC, Yang L, Kong LY. Eucalrobusone C suppresses cell proliferation and induces ROS-dependent mitochondrial apoptosis via the p38 MAPK pathway in hepatocellular carcinoma cells. Phytomedicine 2017; 25: 71-82.

59. Zhu Y, Jiang Y, Shi L, Du L, Xu X, Wang E et al. 7-O-Geranylquercetin induces apoptosis in gastric cancer cells via ROS-MAPK mediated mitochondrial signaling pathway activation. Biomed pharmacother 2017; 87: 527-538.
60. Piao S, Kang M, Lee YJ, Choi WS, Chun YS, Kwak C et al. Cytotoxic effects of escin on human castration-resistant prostate cancer cells through the induction of apoptosis and G2/ M cell cycle arrest. Urology 2014; 84: 982.e981-987.

61. Wang YW, Wang SJ, Zhou YN, Pan SH, Sun B. Escin augments the efficacy of gemcitabine through down-regulation of nuclear factor-kappaB and nuclear factor-kappaB-regulated gene products in pancreatic cancer both in vitro and in vivo. $J$ cancer res clin oncol 2012; 138 : 785-797.

62. Wang Y, Xu X, Zhao P, Tong B, Wei Z, Dai Y. Escin la suppresses the metastasis of triplenegative breast cancer by inhibiting epithelial-mesenchymal transition via down-regulating LOXL2 expression. Oncotarget 2016; 7: 23684-23699.

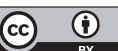

Cell Death and Disease is an open-access journal published by Nature Publishing Group. This work is licensed under a Creative Commons Attribution 4.0 International License. The images or other third party material in this article are included in the article's Creative Commons license, unless indicated otherwise in the credit line; if the material is not included under the Creative Commons license, users will need to obtain permission from the license holder to reproduce the material. To view a copy of this license, visit http://creativecommons.org/licenses/by/4.0/

(C) The Author(s) 2017

Supplementary Information accompanies this paper on Cell Death and Disease website (http://www.nature.com/cddis) 